\title{
Marcadores moleculares na predição do sexo em plantas de mamoeiro
}

\author{
Eder Jorge de Oliveira(1), Jorge Luiz Loyola Dantas(1), Milene da Silva Castellen(1), Diego Souza de Lima(2), \\ Helder de Souza Barbosa ${ }^{(2)}$ e Tiago Borges Nunes Motta(2)
}

\begin{abstract}
(1)Embrapa Mandioca e Fruticultura Tropical, Rua da Embrapa, s/no, Caixa Postal 007, CEP 44380-000 Cruz das Almas, BA. E-mail: eder@cnpmf.embrapa.br, loyola@cnpmf.embrapa.br, milene@cnpmf.embrapa.br (2)Universidade Federal do Recôncavo da Bahia, Campus Universitário de Cruz das Almas, CEP 44380-000 Cruz das Almas, BA. E-mail: diegodelima10@yahoo.com.br, helderbarbosa2007@ig.com.br, tico_motta@hotmail.com
\end{abstract}

Resumo - O objetivo deste trabalho foi validar marcadores moleculares, previamente identificados como ligados ao sexo do mamoeiro, para utilização na seleção indireta em genótipos comerciais. Foram analisadas duas variedades do grupo Solo e dois híbridos do grupo Formosa, com utilização de 20 plantas por genótipo, quatro marcadores do tipo SCAR (Sequence Characterized Amplified Region) e um RAPD (Random Amplified Polymorphic DNA). O RAPD BC210 permitiu a identificação de todas as plantas femininas e hermafroditas, o que revela grande potencial para ser usado na seleção assistida em alguns dos genótipos mais cultivados no Brasil. Os marcadores do tipo SCAR não permitiram a identificação correta do sexo dos genótipos, pois detectou-se a presença de falso-positivos e falso-negativos nas análises.

Termos para indexação: Carica papaya, SCAR, RAPD, identificação sexual.

\section{Molecular markers for sex identification in papaya}

\begin{abstract}
The objective of this work was the validation of previous discovered sex related molecular markers of papaya, aiming at the indirect selection of Brazilian commercial genotypes. Two varieties of the Solo group and two hybrids of the Formosa group (20 plants for genotype), four SCAR (Sequence Characterized Amplified Region) and one RAPD (Random Amplified Polymorphic DNA) markers were used. All hermaphrodite and female plants were correctly predicted by RAPD BC210, showing its high potential for marker assisted selection in important commercial genotypes used in Brazil. The SCAR markers did not show the true sex identification of these genotypes, revealing the presence of false positives and negatives in the analyses.
\end{abstract}

Index terms: Carica papaya, SCAR, RAPD, sexual identification.

\section{Introdução}

O mamoeiro é uma espécie que apresenta flores unissexuais e hermafroditas, que dão origem a plantas do sexo masculino (forma andróica), feminino (ginóica) ou hermafrodita (androginóica) (Marin et al., 1989). Segundo Dantas \& Castro Neto (2000), plantas hermafroditas são preferíveis por produzirem frutos de formato alongado, com variações de piriforme a cilíndrica, pequena cavidade interna e maior valor comercial. As plantas femininas produzem frutos de formato arredondado ou ligeiramente ovalado, cuja cavidade interna é grande, em relação à espessura da polpa, e necessitam da fecundação por pólen de plantas masculinas ou hermafroditas para produzirem frutos (Costa \& Pacova, 2003).
Em plantas hermafroditas, devido ao seu estado heterozigótico para o caráter sexual (Storey, 1938, 1953), é esperada a proporção de 2:1 entre plantas hermafroditas e femininas na descendência autofecundada (Ma et al., 2004). Plantas portadoras dos genótipos $m m, M^{I} m$ e $M^{2} m$ são femininas, masculinas e hermafroditas, respectivamente, enquanto as combinações dominantes são letais zigóticos, de acordo com Hofmeyr (1967). Essa segregação exige que se faça a eliminação das plantas femininas em plantios comerciais, por ocasião do início do florescimento (3-5 meses após o plantio). Como não se conhece o sexo das plantas no início do plantio, os agricultores plantam pelo menos três mudas por cova, o que aumenta os custos de produção, além de afetar o desenvolvimento das plantas hermafroditas em razão da competição (Simão, 1998). 
Metodologias de seleção indireta de plantas hermafroditas ainda na fase de mudas poderiam reduzir os problemas oriundos da sexagem nos plantios comerciais. Nesse sentido, técnicas de diferenciação morfológica, citológica ou molecular têm sido estudadas. Porém, na espécie C. papaya, as duas primeiras alternativas não se mostraram promissoras (Somsri et al., 1998). Assim, o uso de marcadores moleculares possui maior potencial de sucesso (Alstrom-Rapaport et al., 1998).

$\mathrm{O}$ avanço das pesquisas tem permitido resultados positivos, já que alguns marcadores do tipo SCAR (Sequence Characterized Amplified Region) (Parasnis et al., 2000; Deputy et al., 2002; Urasaki et al., 2002; Chaves-Bedoya \& Nuñez, 2007), RAPD (Random Amplified Polymorphic DNA) (Sondur et al., 1996; Deputy et al., 2002; Lemos et al., 2002; Urasaki et al., 2002), microssatélites (Parasnis et al., 1999) e AFLP (Amplified Fragment Length Polymorphism) (Ma et al., 2004) foram desenvolvidos e podem ser utilizados para determinação precoce do sexo das plantas de mamoeiro. Desse modo, a ausência de falso-positivos e falso-negativos na genotipagem sexual é fator preponderante para a escolha de marcas adequadas à seleção assistida por marcadores, ainda na fase de mudas, antes do plantio. Isso se torna mais importante, quando se analisam híbridos de diferentes grupos, com ampla diversidade genética.

Mesmo com as vantagens relacionadas à seleção precoce das plantas hermafroditas, o custo das análises moleculares pode dificultar a difusão dessa metodologia. Entretanto, nos últimos anos, avanços têm sido feitos no que tange à automação de etapas críticas nos trabalhos de diagnose molecular. De acordo com Paris \& Carter (2000), existe a possibilidade de uma pessoa realizar uma triagem completa, desde a extração do DNA até as reações de PCR, em pelo menos 384 plântulas por dia. Dayteg et al. (2007) apresentaram um sistema de genotipagem automática em cevada e canola capaz de analisar cerca de 2.200 amostras por dia a um custo aproximado de $\mathrm{R} \$ 0,62$ por análise. Ao considerar uma cultura implantada com espaçamento de 3,0x2,0 m, e uso de variedades com segregação de 2:1 entre plantas hermafroditas e femininas, o custo das análises por hectare seria de $\mathrm{R} \$ 1.560,00$. Portanto, é possível que essa tecnologia possa ser explorada num futuro próximo.

O objetivo deste trabalho foi validar o uso de marcadores moleculares na identificação sexual de variedades e híbridos de mamoeiro plantados no Brasil, de modo a confirmar a possibilidade de sua utilização em diferentes genótipos.

\section{Material e Métodos}

Foram coletadas amostras de folhas das variedades do grupo Solo, constituído por 'Sunrise Solo' e 'JTA'; e dos híbridos do grupo Formosa, constituído por 'Tainung no 1' e 'Calimosa'. Realizou-se a coleta das folhas na Fazenda São Francisco, Município de Teixeira de Freitas, BA. Utilizaram-se pomares comerciais em fase de produção (10 a 12 meses), amostrando-se dez plantas femininas e dez hermafroditas, em cada cultivar.

As amostras foram acondicionadas em papel-alumínio e armazenadas em ultrafreezer a $80^{\circ} \mathrm{C}$. A extração de DNA foi realizada de acordo com protocolo de Doyle \& Doyle (1990), utilizando-se 0,4\% de 2-mercaptoetanol no tampão de extração, ao invés de $0,2 \%$. A quantificação foi realizada após eletroforese (3 Volts $\mathrm{cm}^{-1}$ ) de alíquotas de cada amostra, pela comparação a uma série de concentrações conhecidas de DNA $(50,100,150 \mathrm{ng})$ do fago $\lambda$, realizada em géis de agarose a $0,8 \%(\mathrm{p} / \mathrm{v})$. A concentração de DNA foi estimada a partir da comparação visual das intensidades das bandas, reveladas pela coloração com brometo de etídio $\left(1,0 \mathrm{mg} \mathrm{mL}^{-1}\right)$.

Os marcadores utilizados na validação foram: RAPD BC210 (Lemos et al., 2002), identificado em plantas femininas, hermafroditas e progênies autofecundadas da variedade Baixinho de Santa Amália; SCAR Cf, identificado em três cultivares de mamoeiro da Colômbia: Catira, ILS647 e ILS649 (Chaves-Bedoya \& Nuñez, 2007); SCAR Napf, desenvolvido com uso de pools de DNA de plantas masculinas e femininas das variedades COII, Pusa Giant e Washington (Parasnis et al., 2000); SCAR SDP, desenvolvido por meio do uso das variedades Sunrise Solo e Waimanalo, linhagens nativas IK-2, IK-7, IK-10 e TK-5, originárias do Japão, bem como a Me-1, originária do México (Urasaki et al., 2002); e SCAR W11, identificado pela técnica de bulk segregante na população $F_{2}$ do cruzamento 'Sunrise Solo' x 'UH 365' (Deputy et al., 2002). Algumas características desses marcadores são descritas na Tabela 1.

As reações em cadeia da polimerase (PCR) para o RAPD BC210 foram realizadas em volume final de $20 \mu \mathrm{L}$, contendo tampão 10X (Invitrogen); $2,25 \mathrm{mM}$ de $\mathrm{MgCl}_{2} ; 150 \mu \mathrm{M}$ de dNTP; $0,225 \mu \mathrm{M}$ do primer; $25 \mathrm{ng}$ de DNA genômico e $1 \mathrm{U}$ de Taq DNA polimerase (Invitrogen). Para o SCAR Cf, utilizou-se volume final de $25 \mu \mathrm{L}$, contendo tampão $10 \mathrm{X} ; 1,5 \mathrm{mM}$ de $\mathrm{MgCl}_{2}$; $200 \mu \mathrm{M}$ de dNTP; $0,2 \mu \mathrm{M}$ de cada primer; $25 \mathrm{ng}$ de 
DNA genômico e 1 U de Taq DNA polimerase. A reação do SCAR Napf continha tampão 10X; $1,5 \mathrm{mM} \mathrm{de} \mathrm{MgCl}_{2}$; $100 \mu \mathrm{M}$ de dNTP; $0,3 \mu \mathrm{M}$ de cada primer; $40 \mathrm{ng}$ de DNA genômico e $1 \mathrm{U}$ de Taq DNA polimerase, em volume final de $25 \mu \mathrm{L}$. As reações do SCAR SDP foram feitas com tampão 10X; $2,5 \mathrm{mM}$ de $\mathrm{MgCl}_{2} ; 200 \mu \mathrm{M}$ de dNTP; $0,5 \mu \mathrm{M}$ de cada primer; 25 ng de DNA genômico e $1 \mathrm{U}$ de Taq DNA polimerase, em volume final de $20 \mu \mathrm{L}$. Nas reações do SCAR W11, utilizou-se um volume final de $25 \mu \mathrm{L}$, contendo tampão $10 \mathrm{X} ; 1,5 \mathrm{mM}$ de $\mathrm{MgCl}_{2}$; $150 \mu \mathrm{M}$ de dNTP; $0,5 \mu \mathrm{M}$ de cada primer; $25 \mathrm{ng}$ de DNA genômico e 1 U de Taq DNA polimerase.

As condições de amplificação seguiram as especificações dos autores que descreveram os marcadores (Parasnis et al., 2000; Deputy et al., 2002; Lemos et al., 2002; Urasaki et al., 2002; Chaves-Bedoya \& Nuñez, 2007), sendo realizadas em termociclador PTC-100 (MJ Research).

Os produtos de amplificação (bandas) foram analisados por eletroforese, em gel de agarose a 1,5\% $(\mathrm{p} / \mathrm{v})$, e visualizados após coloração por brometo de etídio $\left(1,0 \mathrm{mg} \mathrm{mL}^{-1}\right)$, em sistema de fotodocumentação Doc Print II (Vilber Lourmat - Torcy Z.I. - França).

No estudo de validação dos marcadores ligados à herança sexual, as amplificações foram realizadas em duplicatas para verificar a reprodutibilidade dos resultados, principalmente no caso dos iniciadores específicos do tipo SCAR. Este último marcador revela um padrão de banda único para o alelo desejado. Assim, a ausência de bandas implica em falhas na PCR ou a real ausência do alelo de interesse.

Em todos os marcadores, as bandas estão presentes nas plantas hermafroditas e ausentes nas femininas (Parasnis et al., 2000; Deputy et al., 2002; Lemos et al., 2002; Urasaki et al., 2002; Chaves-Bedoya \& Nuñez, 2007), o que indica a existência de ligação específica ao alelo $M^{2}$ (Hofmeyr, 1967). Assim, na análise dos dados, as plantas sabidamente femininas, que possuíam as marcas, foram consideradas como falso-positivas e as hermafroditas sem os alelos, como falso-negativas.

\section{Resultados e Discussão}

A amplificação do marcador RAPD BC210 revelou a presença de uma banda única, com 438 pares de bases $(\mathrm{pb})$, exclusivamente em plantas hermafroditas de todas as variedades e híbridos analisados (Figura 1). Lemos et al. (2002) também avaliaram a possibilidade de uso deste marcador nas variedades Sunrise Solo e Improved Sunrise Solo 72/12. Os resultados alcançados neste trabalho foram concordantes com os apresentados por esses autores, sem nenhum produto de amplificação nas plantas femininas, de ambas as variedades, e presença do alelo alvo nas plantas hermafroditas.

As amplificações com o SCAR Cf indicaram a presença de bandas falso-positivas apenas na variedade JTA e no híbrido Tainung no 1 (Figura 2). Foram identificadas cinco plantas fêmeas com bandas de alta intensidade (plantas 1, 6, 7, 8 e 9) e outras três com bandas menos intensas (plantas 2, 3 e 4), na variedade JTA (Figura 2 B). Nessa variedade, observou-se a presença de falso-positivo em $90 \%$ das plantas. No híbrido Tainung no 1 , as plantas $1,2,9$ e 10 (Figura 2 C) também apresentaram o mesmo comportamento, com $40 \%$ de plantas com diagnóstico falso-positivo. Esse alto porcentual de erros, na genotipagem, limita o uso desse marcador no processo de identificação sexual de variedades e híbridos comerciais de mamoeiro cultivados comercialmente no Brasil.

Da mesma forma que o SCAR Cf, o uso do SCAR Napf identificou falso-positivos com bandas de alta intensidade na variedade JTA (plantas $1,6,7,8$ e 9) e no híbrido Tainung $\mathrm{n}^{\circ} 1$ (plantas 1, 9 e 10) (Figura 3).

Tabela 1. Marcadores moleculares ligados ao sexo do mamoeiro.

\begin{tabular}{lllcl}
\hline Tipo de marcador & Nome do primer & \multicolumn{1}{c}{ Seqüência } & Tamanho do alelo (pb) & \multicolumn{1}{c}{ Referência } \\
\hline RAPD & BC210 & GCACCGAGAG & 438 & Lemos et al. (2002) \\
\hline SCAR Napf & Napf76 & GAGGATCCCTATTAGTGTAAG & 831 & Parasnis et al. (2000) \\
& Napf77 & GAGGATCCCTTTTGCACTCTG & & Urasaki et al. (2002) \\
\hline SCAR SDP & SDP1 & GCACGATTTAGATTAGATGT & 225 & Deputy et al. (2002) \\
& SDP2 & GGATAGCTTGCCCAGGTCAC & & \\
\hline SCAR W11 & W11-F & CTGATGCGTGTGTGGCTCTA & 800 & Chaves-Bedoya \& Nuñez (2007) \\
& W11-R & CTGATGCGTGATCATCTACT & & \\
\hline
\end{tabular}


Nas quatro cultivares testadas, detectaram-se outros falso-positivos, porém com baixa intensidade, como se observa nas plantas 5 e 10 da variedade Sunrise Solo (Figura $3 \mathrm{~A}$ ); plantas 2, 3 e 4 da variedade JTA(Figura 3 B); plantas 2, 3 e 4 do híbrido Tainung no 1 (Figura 3 C); e plantas 1 e 9 do híbrido Calimosa (Figura 3 D). Ao considerar todos os genótipos avaliados, independentemente da intensidade de bandas, a presença de falso-positivos foi de 20, 80, 60 e 20\%, nos genótipos Sunrise Solo, JTA, Tainung $\mathrm{n}^{\mathrm{o}} 1$ e Calimosa, respectivamente.
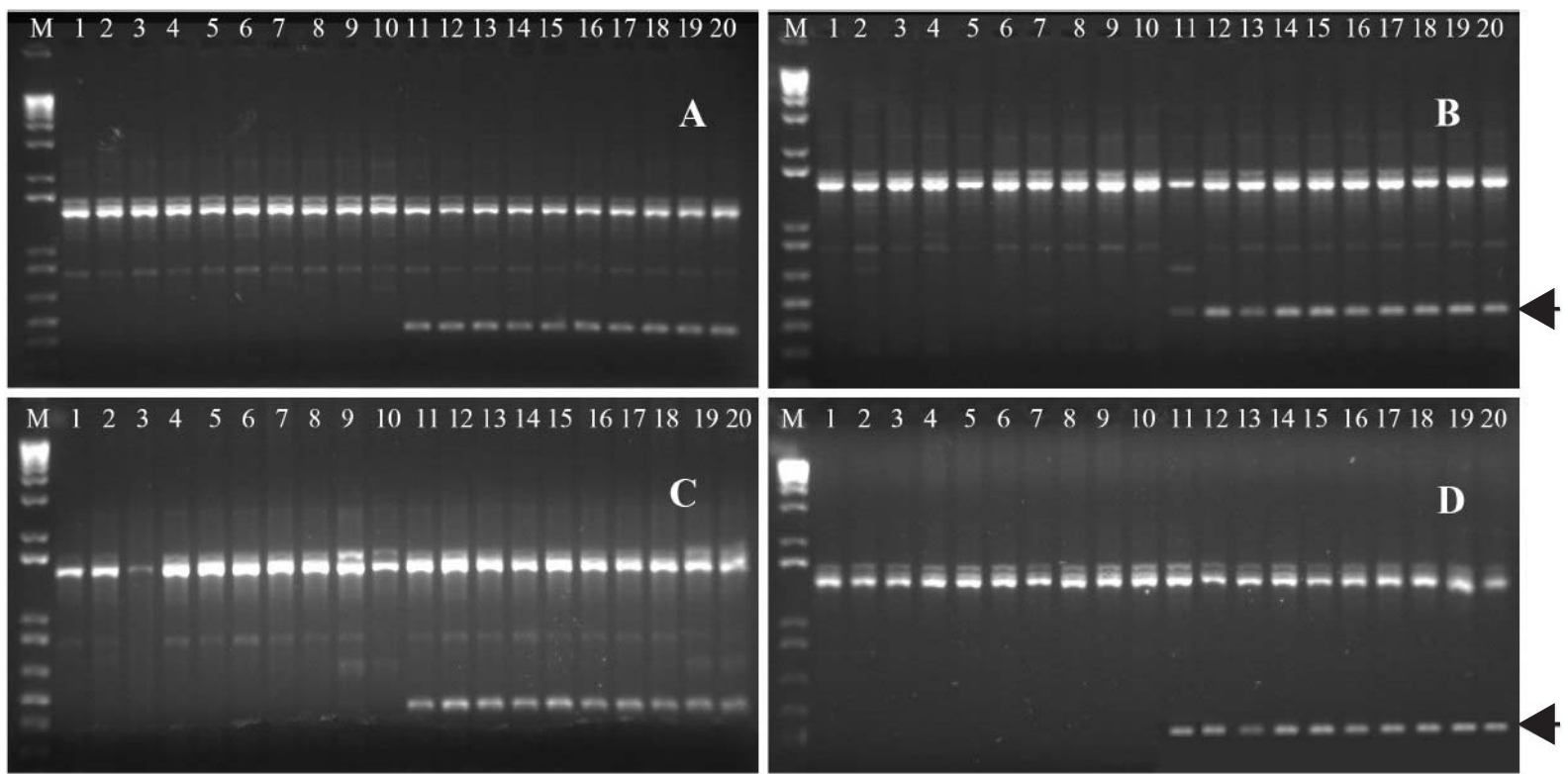

Figura 1. Amplificação do DNA de mamoeiro com o RAPD BC210. M: Ladder $1 \mathrm{~kb}$ plus (Invitrogen). Em todas as figuras, as amostras de 1 a 10 são plantas femininas, e de 11 a 20, hermafroditas. A) variedade Sunrise Solo; B) variedade JTA; C) híbrido Tainung no 1; D) híbrido Calimosa. A seta indica o tamanho do alelo esperado (438 pb).
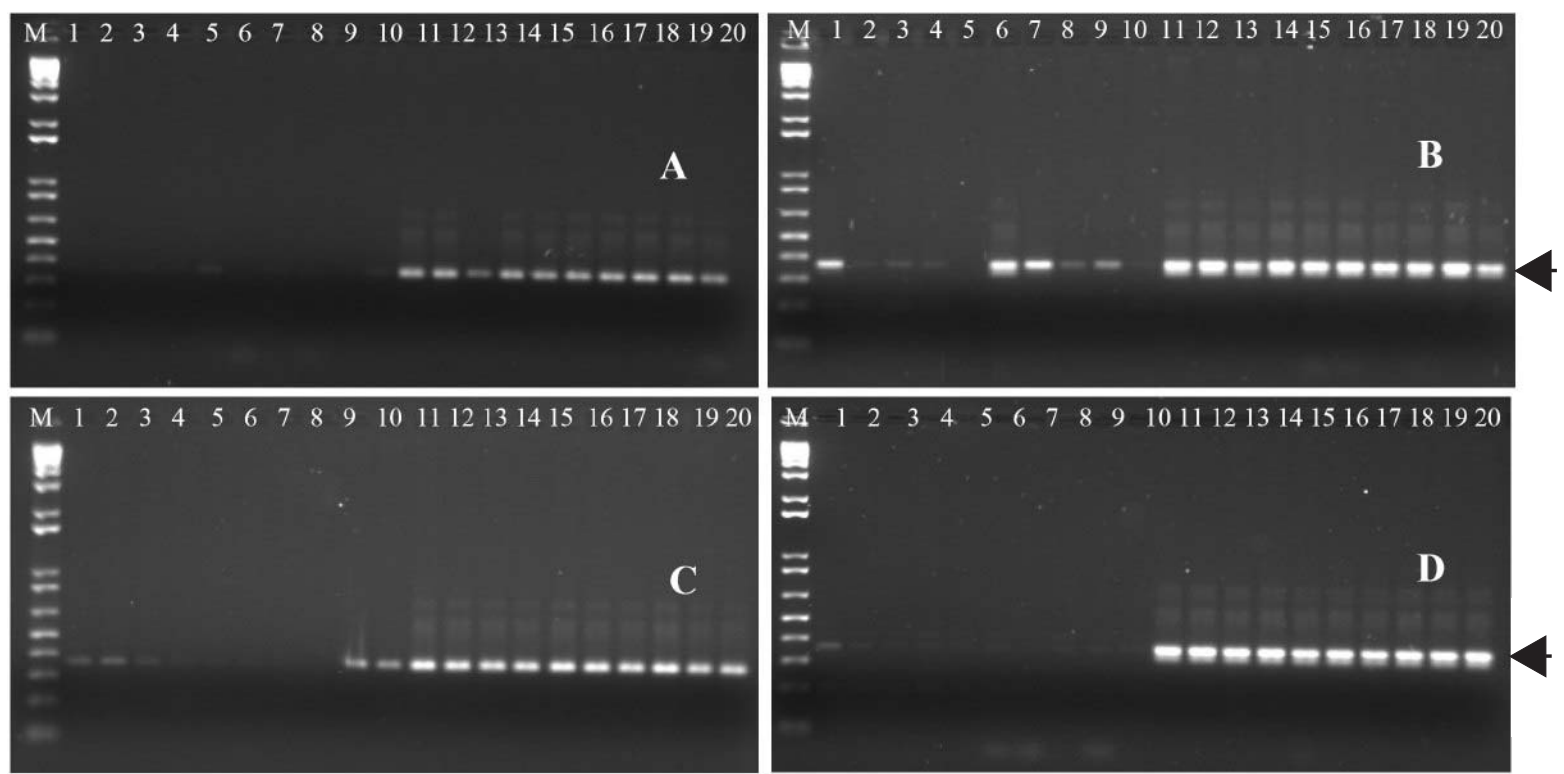

Figura 2. Amplificação do DNA de mamoeiro com o SCAR Cf. M: Ladder 1 kb plus (Invitrogen). Em todas as figuras, as amostras de 1 a 10 são plantas femininas, e de 11 a 20, hermafroditas. A) variedade Sunrise Solo; B) variedade JTA; C) híbrido Tainung no 1; D) híbrido Calimosa. A seta indica o tamanho do alelo esperado (369 pb). 
Na análise de 12 variedades dióicas de mamoeiro, oriundas da Índia, o SCAR Napf apresentou confiabilidade de $98 \%$ (Parasnis et al., 2000). Os genótipos utilizados neste trabalho foram do tipo ginóico-andromonóicos, ou seja, não havia plantas masculinas, e, mesmo assim, houve identificação completa de todas as plantas hermafroditas, provavelmente decorrente da conservação desse loco nessa forma sexual.

Por sua vez, o marcador SCAR SDP não apresentou nenhum falso-positivo nas variedades Sunrise Solo e no híbrido Calimosa (Figura 4 A e D). Na variedade JTA,
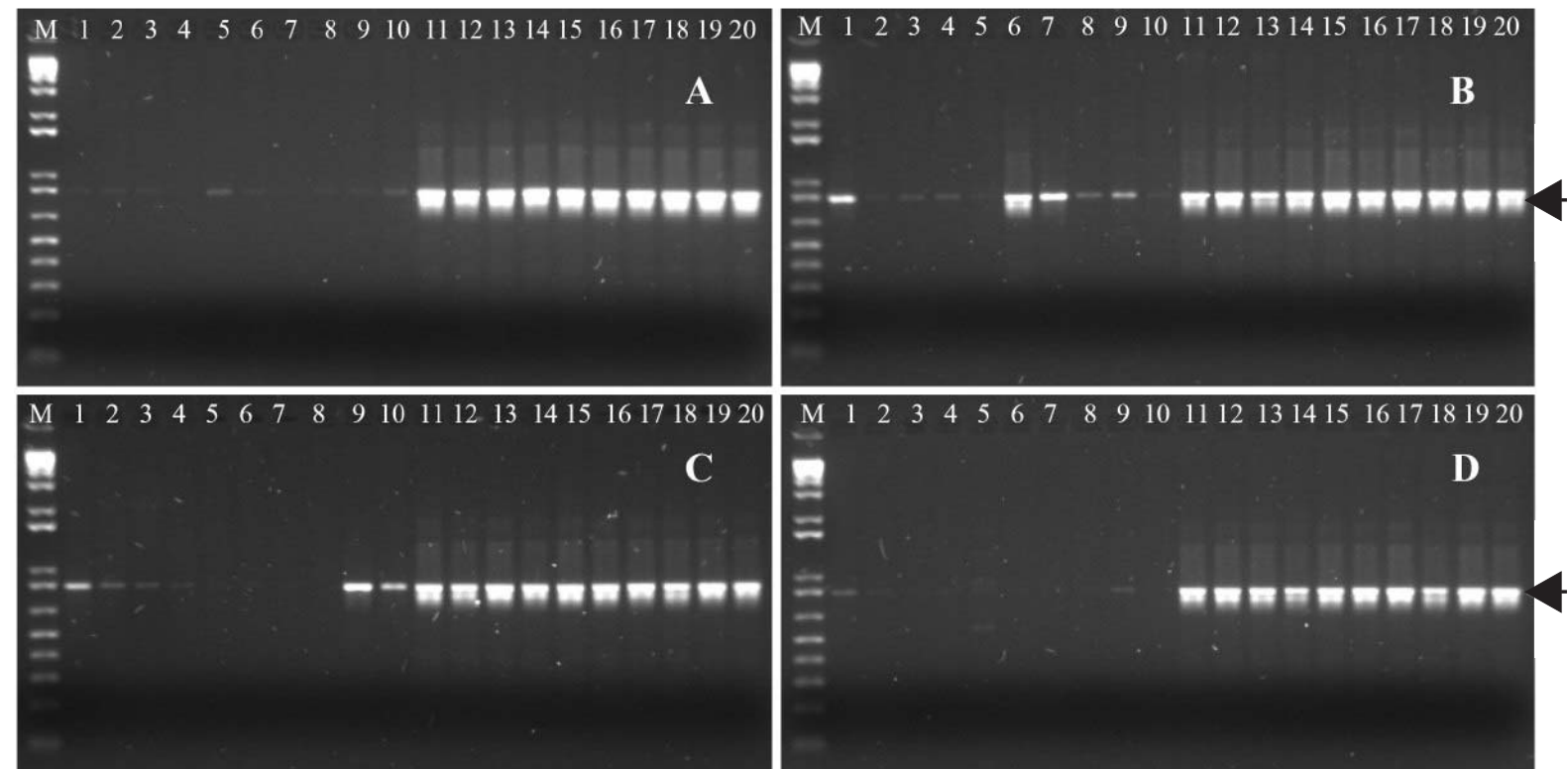

Figura 3. Amplificação do DNA de mamoeiro com o SCAR Napf. M: Ladder 1 kb plus (Invitrogen). Em todas as figuras, as amostras de 1 a 10 são plantas femininas, e de 11 a 20, hermafroditas. A) variedade Sunrise Solo; B) variedade JTA; C) híbrido Tainung no 1; D) híbrido Calimosa. A seta indica o tamanho do alelo esperado (831 pb).
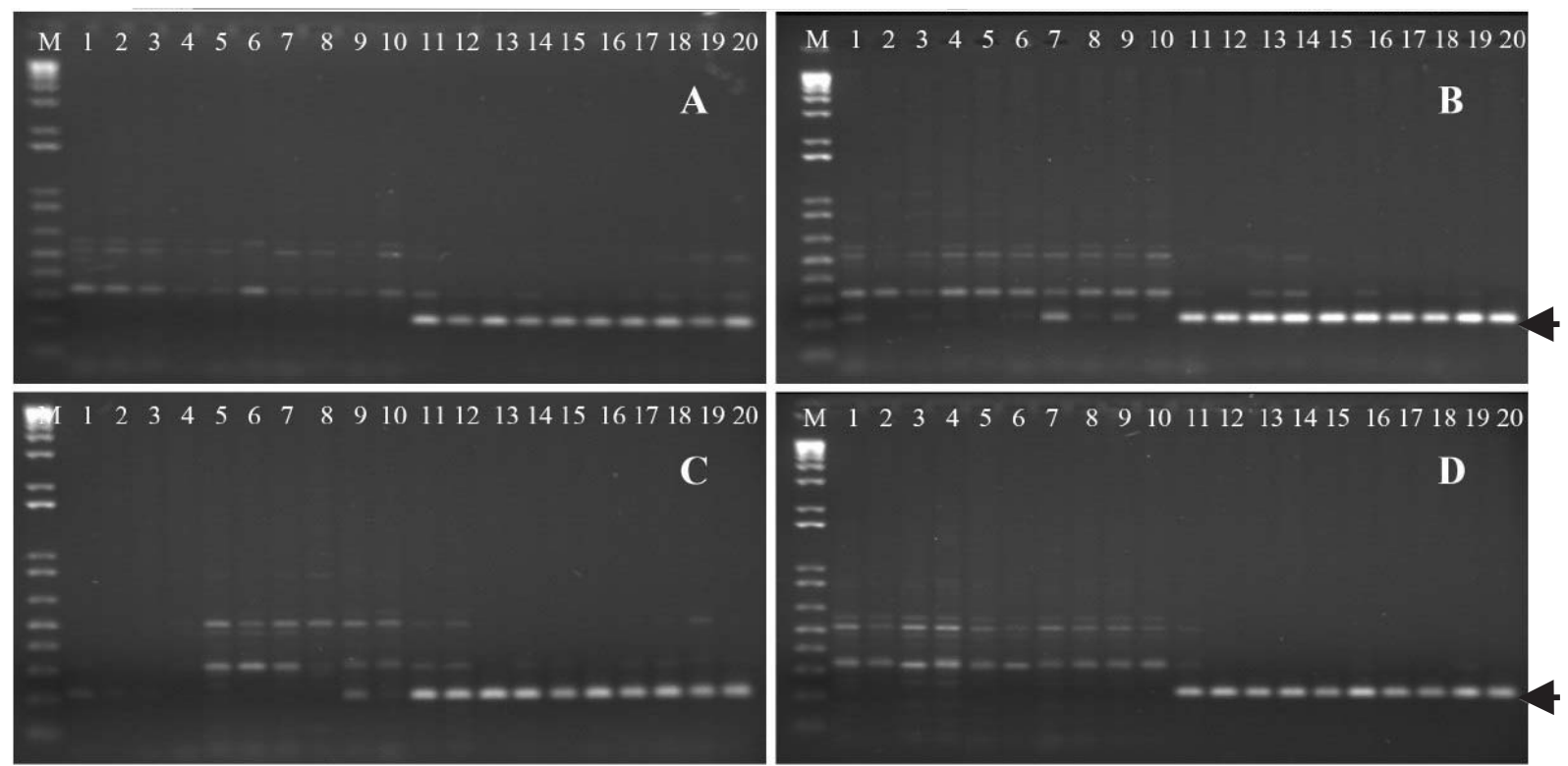

Figura 4. Amplificação do DNA de mamoeiro com o SCAR SDP. M: Ladder $1 \mathrm{~kb}$ plus (Invitrogen). Em todas as figuras, as amostras de 1 a 10 são plantas femininas, e de 11 a 20, hermafroditas. A) variedade Sunrise Solo; B) variedade JTA; C) híbrido Tainung no 1; D) híbrido Calimosa. A seta indica o tamanho do alelo esperado (225 pb). 
as plantas 7 e 9 apresentaram o fragmento de $225 \mathrm{pb}$, que identifica as masculinas e hermafroditas (Figura 4 B). O mesmo aconteceu com a planta 9 do híbrido Tainung no 1 (Figura 4 C). A porcentagem de falso-positivos foi de $20 \%$ na variedade JTA e de $10 \%$ no híbrido Tainung no 1 , o que restringe o uso desse marcador na seleção assistida. Em concordância com os outros marcadores, o SCAR SDP não proporcionou nenhum falso- negativo nas cultivares estudadas (Figura 4).

No caso do SCAR W11, foram encontradas tanto plantas falso-positivas quanto falso-negativas. Observaram-se duas plantas falso-positivas (6 e 7) para a variedade JTA (Figura $5 \mathrm{~B}$ ) e uma para o híbrido Tainung no 1 (Figura 5 C). No caso do híbrido Calimosa, foi observada a presença de uma planta falso-negativa (planta 18) (Figura 5 D).

De acordo com os dados obtidos, o SCAR W11 encontra-se distante dos genes que conferem a diferenciação sexual do mamão, uma vez que foram encontradas tanto plantas falso-positivas quanto falsonegativas em todas as cultivares avaliadas. Assim, existe baixo potencial de uso desse marcador para a predição do sexo do mamoeiro de forma precoce, nos genótipos de mamoeiro mais utilizados no sistema de produção nacional.
A presença de fragmentos, especificamente associados ao hermafroditismo, em algumas plantas do sexo feminino e não em outras, indica a heterogeneidade dessas variedades e híbridos nos locos analisados pelos marcadores BC210, Cf, Napf, SDP e W11. Esses falsopositivos apareceram principalmente na variedade local JTA (extremo sul da Bahia) e no híbrido Tainung no 1 . No caso da 'JTA', uma hipótese que pode explicar essa heterogeneidade entre plantas refere-se ao processo de obtenção das sementes para os plantios. Os produtores escolhem as plantas para a coleta das sementes pelo seu padrão, vigor, produtividade e qualidade de frutos, sem fazer a proteção das flores e o devido controle das polinizações. Assim, mesmo o elevado grau de autopolinização dessa variedade não garante a qualidade e a pureza das sementes. O fato de o mamoeiro ser propagado basicamente por sementes, aliado à facilidade do cruzamento natural, faz com que as mudas resultantes deste processo sejam bastante variáveis. No caso do 'Tainung no 1', é possível que as linhagens utilizadas para a produção do híbrido $F_{1}$ não sejam completamente homozigóticas para alguns locos, o que pode ter ocasionado segregações para os marcadores SCAR.

Neste trabalho, a presença de plantas falso-negativas ocorreu especificamente com o uso do SCAR W11. Este marcador foi desenvolvido com o uso de populações
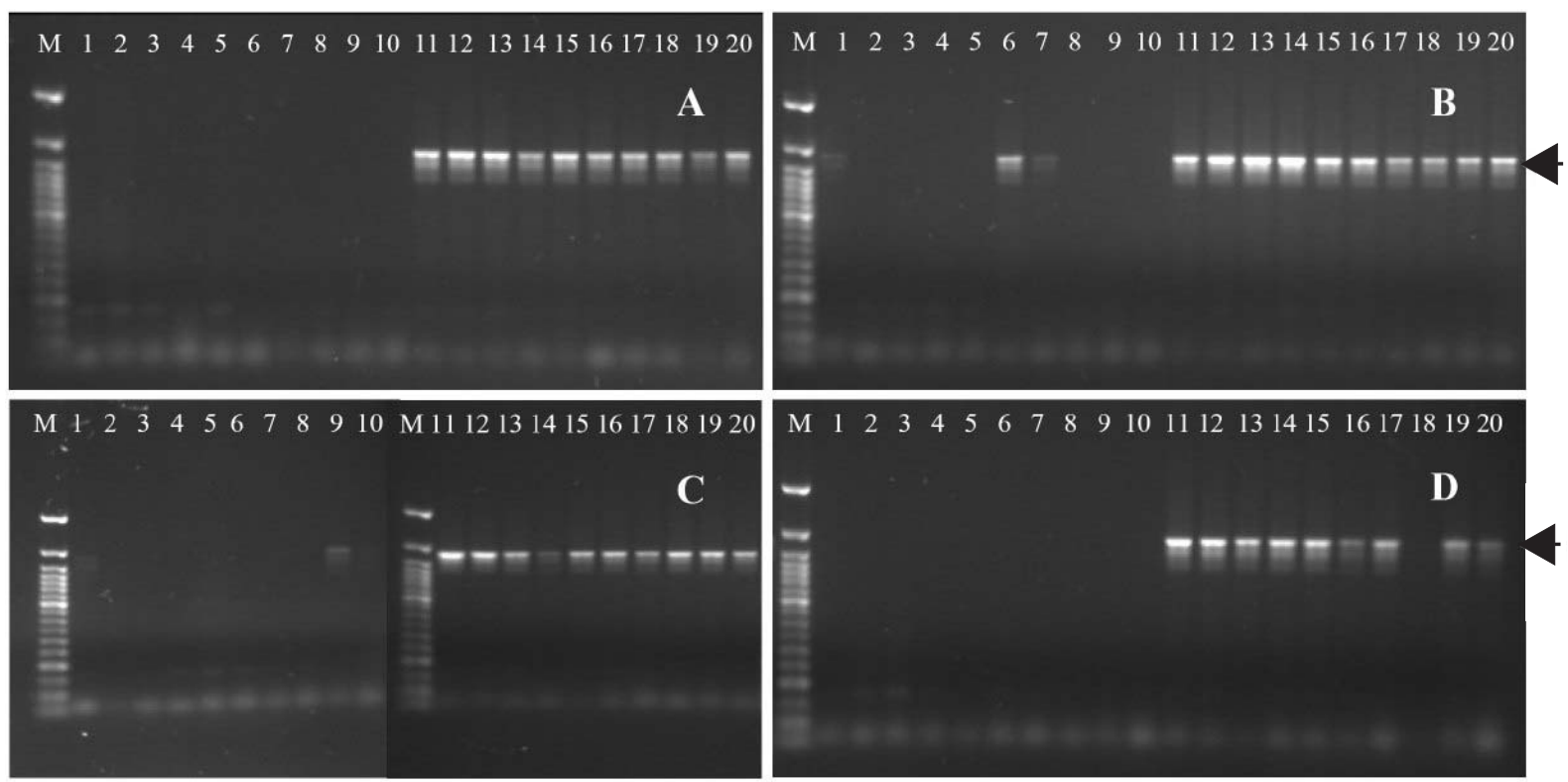

Figura 5. Amplificação do DNA de mamoeiro com o SCAR W11. M: Ladder 50 pb (New England Biolabs Inc.). Em todas as figuras, as amostras de 1 a 10 são plantas femininas, e de 11 a 20, hermafroditas. A) variedade Sunrise Solo; B) variedade JTA; C) híbrido Tainung no 1 ; D) híbrido Calimosa. A seta indica o tamanho do alelo esperado (800 pb). 
segregantes $F_{2}$ (Deputy et al., 2002), por isso, é possível que a ligação ao alelo que condiciona o sexo masculino e hermafrodita ocorra somente quando os locos marcadores estejam em máximo desequilíbrio de ligação.

Plantas falso-positivas e falso-negativas também foram verificadas por Deputy et al. (2002) com o uso desse marcador, ao analisar variedades de mamão dióicas e ginóico-andromonóicas. As variedades Mardi, originária da Malásia, e Honey Dew, da Índia, apresentaram 40 e $20 \%$ de plantas femininas com a presença do fragmento de $800 \mathrm{pb}$, respectivamente. Além disso, esses autores alcançaram 99,2\% de sucesso na identificação de plantas hermafroditas de gerações segregantes dos cruzamentos 'Rainbow' x 'Laie Gold' e 'Rainbow' x 'Poamoho Gold'.

Uma explicação para a dificuldade de se encontrar marcas ligadas especificamente às plantas femininas advém do fato de que a triagem inicial da análise de ligação é feita com marcadores dominantes como o RAPD. Nesse caso, os fragmentos de RAPD são clonados e transformados em marcadores específicos (SCAR). Como as plantas $\mathrm{mm}, \mathrm{M}^{\mathrm{l}} \mathrm{m}$ e $M^{2} m$ são femininas, masculinas e hermafroditas, respectivamente (Hofmeyr, 1967), a identificação de marcadores ligados ao alelo $m$ estaria presente em todos os tipos sexuais.

A amplificação dos alelos, tanto nas plantas masculinas quanto nas hermafroditas, parece consistente do ponto de vista biológico, já que a região específica do cromossomo responsável pela determinação sexual no mamoeiro deve ter um segmento idêntico em ambos os sexos, e está ausente nas femininas (Chavez-Bedoya \& Nuñez, 2007). Essa região parece apresentar certa conservação entre gêneros, já que o fragmento de $800 \mathrm{pb}$, gerado pelo marcador RAPD OPF 2, identifica as plantas masculinas e hermafroditas tanto em Vasconcellea cauliflora quanto em C. papaya (Parasnis et al., 2000).

\section{Conclusões}

1. O marcador RAPD BC210 apresenta capacidade em discriminar o sexo do mamoeiro, e tem seu uso validado para determinação sexual de alguns dos genótipos mais plantados no Brasil.

2. A precisão dos marcadores do tipo SCAR é variável entre os genótipos analisados, o que resulta em limitações para uso no processo de seleção assistida por marcadores moleculares.
3. Há variações moleculares em variedades e híbridos $\mathrm{F}_{1}$ de mamoeiro, ainda não detectadas por causa do alto grau de homozigose das linhagens genitoras dos híbridos e das variedades.

\section{Referências}

ALSTROM-RAPAPORT, C.; LASCOUX, M.; WANG, Y.C.; ROBERTS, G.; TUSKAN, G.A. Identification of a RAPD marker linked to sex determination in the basket willow (Salix viminalis L.). Journal of Heredity, v.89, p.44-49, 1998.

CHAVES-BEDOYA, G.; NUÑEZ, V. A SCAR marker for the sex types determination in Colombian genotypes of Carica papaya. Euphytica, v.153, p.215-220, 2007.

COSTA, A.F.S.; PACOVA, B.E.V. Caracterização de cultivares, estratégias e perspectivas do melhoramento genético do mamoeiro. In: MARTINS, D.S.; COSTA, A.F.S. (Ed.). A cultura do mamão: tecnologia e produção. Vitória: Incaper, 2003. p.59-102.

DANTAS, J.L.L.; CASTRO NETO, M.T. Aspectos botânicos e fisiológicos. In: TRINDADE, A.V. (Org.). Mamão, produção: aspectos técnicos. Brasília: Embrapa Comunicação para Transferência de Tecnologia, 2000. p.11-14.

DAYTEG, C.; TUVESSON, S.; MERKER, A.; JAHOOR, A.; KOLODINSKA-BRANTESTAM, A. Automation of DNA marker analysis for molecular breeding in crops: practical experience of a plant breeding company. Plant Breeding, v.126, p.410-415, 2007.

DEPUTY, J.C.; MING, R.; MA, H.; LIU, Z.; FITCH, M.M.M.; WANG, M.; MANSHARDT, R.; STILES, J.I. Molecular markers for sex determination in papaya (Carica papaya $\mathrm{L}$.). Theoretical and Applied Genetics, v.106, p.107-111, 2002.

DOYLE, J.J.; DOYLE, J.L. Isolation of plant DNA from fresh tissue. Focus, v.12, p.13-15, 1990.

HOFMEYR, J.D.J. Some genetic breeding aspects of Carica papaya L. Agronomia Tropical, v.17, p.345-351, 1967.

LEMOS, E.G.M.; SILVA, C.L.S.P.; ZAIDAN, H.A. Identification of sex in Carica papaya L. using RAPD markers. Euphytica, v.127, p.179-184, 2002.

MA, H.; MOORE, P.H.; LIU, Z.; KIM, M.S.; YU, Q.; FITCH, M.M.M.; SEKIOKA, T.; PATERSON, A.H.; MING, R. High density linkage mapping revealed suppression of recombination at the sex determination locus in papaya. Genetics, v.166, p.419-436, 2004.

MARIN, S.L.D.; GOMES, J.A.; ALVES, F.L. Introdução, avaliação e seleção do mamoeiro cv. Improved Sunrise Solo Line 72/12 no Estado do Espírito Santo. Vitória: Emcapa, 1989. 13p. (Emcapa, Documentos, 59).

PARASNIS, A.S.; GUPTA, V.S.; TAMHANKAR, S.A.; RANJEKAR, P.K. A highly reliable sex diagnostic PCR assay for mass screening of papaya seedlings. Molecular Breeding, v.6, p.337-344, 2000.

PARASNIS, A.S.; RAMAKRISHNA, W.; CHOWDARI, K.V.; GUPTA, V.S.; RANJEKAR, P.K. Microsatellite (GATA) $n$ reveals sex specific differences in papaya. Theoretical and Applied Genetics, v.99, p.1047-1052, 1999. 
PARIS, M.; CARTER, M. Cereal DNA: A rapid high throughput extraction method for marker assisted selection. Plant Molecular Biology Reporter, v.18, p.357-360, 2000.

SIMÃO, S. Mamão. In: SIMÃO, S. Tratado de Fruticultura. Piracicaba: Fealq, 1998. p.541-575.

SOMSRI, S.; FLETCHER, R.J.; DREW, R.; JOBIN-DÉCOR, M.; LAWSON, W.; GRAHM, M. Developing molecular markers for sex prediction in papaya (Carica papaya L.). Acta Horticulturae, v.461, p.141-148, 1998.

SONDUR, S.N.; MANSHARDT, R.M.; STILES, J.I. A genetic linkage map of papaya based on randomly amplified polymorphic
DNA markers. Theoretical and Applied Genetics, v.93, p.547-553, 1996.

STOREY, W.B. Genetics of papaya. Journal of Heredity, v.44, p.70-78, 1953.

STOREY, W.B. Segregation of sex type in Solo papaya and their application to the selection of seed. Proceedings of the American Society for Horticultural Science, v.35, p.83-85, 1938.

URASAKI, N.; TOKUMOTO, M.; TARORA, K.; BAN, T.; KAYANO, T.; TANAKA, H.; OKU, H.; CHINEN, I.; TERAUCHI, R. A male and hermaphrodite specific RAPD marker for papaya (Carica papaya L.). Theoretical and Applied Genetics, v.104, p.281-285, 2002.

Recebido em 30 de agosto de 2007 e aprovado em 14 de novembro de 2007 